Preprints of the

Max Planck Institute for

Research on Collective Goods

Bonn 2009/23

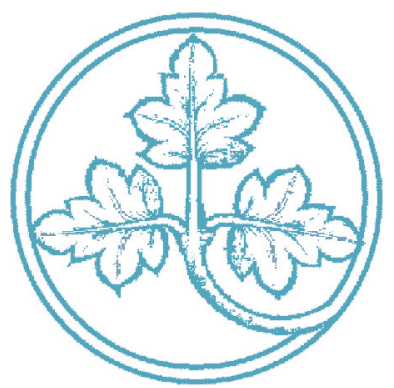

Sticky Rebates:

Target Rebates Induce

Non-Rational Loyalty in Consumers

Alexander Morell Andreas Glöckner

Emanuel Towfigh

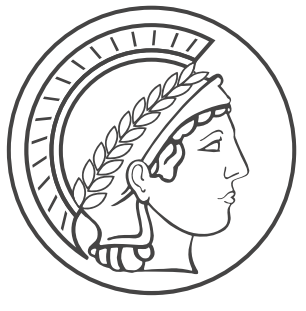




\section{Sticky Rebates: Rollback Rebates Induce Non-Rational Loyalty in Consumers - Experimental Evidence}

Alexander Morell / Andreas Glöckner / Emanuel Towfigh

July 2009

revised February 2013 


\title{
Sticky Rebates: \\ Target Rebates Induce Non-Rational Loyalty in Consumers ${ }^{\dagger}$
}

by

\author{
Alexander Morell", Andreas Glöckner \& Emanuel Towfigh
}

\begin{abstract}
Competition policy often relies on the assumption of a rational consumer, although other models may better account for people's decision behavior. In three experiments, we investigate the influence of loyalty rebates on consumers based on the alternative Cumulative Prospect Theory (CPT), both theoretically and experimentally. CPT predicts that loyalty rebates could harm consumers by impeding rational switching from an incumbent to an outside option (e.g., a market entrant). In a repeated trading task, participants decided whether or not to enter a loyalty rebate scheme and to continue buying within that scheme. Meeting the condition triggering the rebate was uncertain. Loyalty rebates considerably reduced the likelihood that participants switched to a higher-payoff outside option later. We conclude that loyalty rebates may inflict substantial harm on consumers and may have an underestimated potential to foreclose consumer markets.
\end{abstract}

Keywords: Biases; Prospect theory; Consumer decision-making; Rebates; Antitrust

APA-Codes: 3920; 2340; 4200

$\dagger \quad$ We thank Pinar Akman, Martin Beckenkamp, Carsten Burhop, Christoph Engel, Scott Hemphill, Jos Jansen, Botond Köszegi, Sebastian Kube, Michael Kurschilgen, Marc Jekel, Marco Spallone, the participants of a seminar at the CCP Norwich in 2008, of a Behavioral Law \& Economics workshop in Munich in 2008, of the CLEEN Meeting in Tilburg 2009, at the panel for experimental law and economics at the ALEA annual meeting 2009, at the "Consumer Protection" panel at the EALE annual meeting in Rome 2009, and at the Conference on Empirical Legal Studies in Stanford 2012 for helpful comments on earlier versions of this paper.

* Correspondence concerning this paper should be addressed to: Alexander Morell, Max Planck Institute for Research on Collective Goods, Kurt-Schumacher-Str. 10, D-53113 Bonn, Phone: +49-(0) 228 / 914 16 0, E-mail: morell@coll.mpg.de 


\section{Introduction}

Loyalty consumer rebates are omnipresent. The average US household is reported to participate in 6.2 loyalty programs (Dreze \& Nunes 2011). Airlines offer "frequent flyer programs", and Best Buy's "Reward Zone" is another popular example of a loyalty rebate. Several European fashion stores (e.g., Anson's, Peek \& Cloppenburg) run loyalty rebate schemes. Many of these loyalty programs imply a conditional element. Airlines entitle customers to preferential service, premiums, or bonus miles conditional on them having traveled more than a predefined amount of miles per year; hotel chains and clothing retailers offer similar deals. If the threshold triggering the rebate is set right, these rebates can effectively take the form of a market share discount.

What if consumers frame these conditional rebates as a task of pursuing a goal? The first sentence Lufthansa, a German airline, wrote to its customers when introducing a new conditional rebate was: "Dear Mr./Mrs. X, do you know the marvelous feeling of having reached a goal you set yourself?" Marketing professionals do not write a single word without a second thought. It is possible - and this is what we will explore in this paper - that goals shift reference points upwards so that foregoing the rebate seems like a loss. Once marketers have succeeded in shifting customers' reference point according to prospect theory (Kahneman \& Tversky, 1979, details below), the latter will be more reluctant to switch to a different supplier not to "lose" the rebate - a psychological switching cost.

There is empirical evidence, for instance, that an airline dominating a hub airport can use frequent flyer programs to foreclose smaller but equally efficient competitors from the market (Lederman 2007). This makes loyalty programs a potential issue of antitrust law prohibiting dominant firms to foreclose markets inefficiently (Sec. 2 Sherman Act [ShA] and Art. 102 Treaty on the Functioning of the European Union [TFEU]). Conditional loyalty rebates inducing psychological switching costs may either explain parts of findings like the one by Lederman or exacerbate them. Also, as the described psychological switching cost is to the detriment of consumers, one may consider action under consumer protection laws.

Laypersons (Tversky \& Kahneman, 1974) and even expert decision makers (Koehler, Brenner, \& Griffin, 2002) have serious trouble making intelligent judgments in situations of risk and uncertainty (see Rabin, 1998, for a review). Being widely accepted in psychological decision research, the systematic deviations from rational choice led economists to conclude that the "orthodox economic model [...] does a poor job of predicting the behavior of the average consumer" (Thaler, 1980, p. 58). Alternative models have been suggested to account better for consumer behavior. Arguably the most influential approach is Prospect Theory (Kahneman \& Tversky, 1979), together with its advancements (Schmidt, Starmer, \& Sugden, 2008; Tversky \& Kahneman, 1992).

Interestingly, however, deviations from rationality have only very recently gained the attention of scholars and practitioners in competition law. Several recent publications have 
launched a vibrant debate about "behavioral antitrust". The rule of reason on retail price maintenance, for example, has been reevaluated using insights from behavioral economics for assessing decisions of firms to apply retail price maintenance (Tor \& Rinner 2011). Further subjects of study were behavioral merger control (Stucke 2007; Reeves \& Stucke 2011) and behavioral market entry (Tor 2002). This new direction of research received a lot of attention and support (see, e.g., a special issue of Competition Policy International in 2010; the conference web site http://behavioralantitrust.acle.nl; the speech by Federal Trade Commissioner Rosch, 2010), but it was also criticized for making welfare analysis impossible, for applying insights derived from a student subject pool to firm behavior, and for pursuing a paternalistic agenda (Werden, Froeb, \& Shor 2011).

The most promising applications of behavioral antitrust have dealt with consumer behavior. Replacing a standard demand function with a more realistic model of consumer behavior often leads to very different predictions in situations highly relevant to antitrust (see the survey report to the British Office of Fair Trading by Huck et al. 2011). The criticism of extrapolating insights from observed behavior of participants in lab experiments (most of whom are students) to corporate behavior cannot be leveled when thinking about consumer behavior because students are typically consumers in many markets. Additionally, the paternalism argument has less bite in consumer protection contexts because consumer protection law specifically aims at protecting consumers where they cannot protect themselves.

Our paper contributes both to finding a more realistic model of consumer behavior in the context of rebates for the purpose of antitrust and to finding situations where non-moneymaximizing behavior of consumers may suggest granting them some protection.

For this purpose, we investigate the influence of loyalty rebates on consumers' behavior. Applying Cumulative Prospect Theory (Tversky \& Kahneman, 1992) as a candidate model of consumer behavior, we predict and find that conditional loyalty rebates induce a psychological switching cost. By means of these switching costs, conditional rebates are a potential tool for inefficient market foreclosure and may directly harm consumers. With regard to antitrust law and to consumer protection law, our findings provide an argument to intensify the scrutiny rebates are subject to.

\subsection{Loyalty Rebates: Definition and Examples}

By Loyalty rebate we refer to a pricing scheme that grants a significant price reduction on all units bought during a certain reference period if the customer transgresses a certain threshold in purchases within that reference period. A couple of years ago, Lufthansa, the largest German airline, offered its customers a particularly clean example of a loyalty rebate scheme. Customers were incited to set their own target for flying a certain number of miles within a year (i.e., reference period) and received a discount (i.e., further bonus miles) on all purchases only if they reached the threshold. Loyalty rebates are sometimes very simple (e.g., if you buy 
more than $x$ within $t$, you receive $y \%$ discount on everything), but can also include several targets that yield increasing rebates. When consumers want to make rational decisions in these schemes, they have to predict their demand. This prediction will often be uncertain due to the influence of many unknown factors. Therefore such rebates place the customer in a situation of risk or even uncertainty. ${ }^{1}$ We hypothesize that by inducing this uncertainty and moving the point of reference (for details, see below), loyalty rebates impose an additional, and so far underestimated, psychological switching cost on consumers. This switching cost ultimately has detrimental effects on markets, which should be taken into account in the legal assessment and regulation of rebates.

\subsection{Regulation of Loyalty Rebates in Europe and in the US}

Rebates are high on the agenda of competition policy both in the US and the EU. In both jurisdictions, a tendency is emerging to consider the psychology of buying behavior in practice.

US Courts used to take a rather lenient position towards loyalty rebates, in particular if they only concerned one product (see, for example, the case Concord Boat v. Brunswick). Although single product rebates long seemed to be legal per se, recent cases like $A M D$ vs. Intel or ZF Meritor vs. Eaton have shown that conditional rebates can lead to expensive settlements or even to antitrust liability under Sec. 2 Sherman Act. American Courts start to worry about the potential of conditional rebates to serve as substitutes for exclusive dealing arrangements and to foreclose markets inefficiently.

Even in the single product case, European antitrust authorities have long been concerned about detrimental effects of loyalty rebates generating a discontinuity in the pricing function that may cause a 'suction effect' (see below). But on top of these effects conditional rebates may have on rational buyers, European Authorities now worry about the "weak psychological position" rebates place buyers in (COMP/E-2/36.041/PO - Michelin, no. 224, a case concerning small professional buyers, see also section 2.1. of this paper). For both, the standard and the psychological reasons, the European Commission and the European Courts have suppressed loyalty and target rebates applied by dominant companies per se unless their reference period was shorter than three months (Hoffmann-LaRoche v. Commission; Michelin v. Commission I.; British Airways v. Commission; Michelin v. Commission II.; Intel v. Commission; Tomra v. Commission). For the future, the European Commission included rebates among its enforcement priorities under Art. 102 TFEU (DG Competition 2005; European Commission 2009).

Even though we are not aware of any US antitrust decision or opinion explicitly referring to any psychological state of mind, we understand the Supreme Court's distinction between 'soapproximation, while under uncertainty, probabilities are unknown. 
phisticated' and 'unsophisticated' consumers to point into a similar direction. Information cost can be both, organizational or cognitive. And psychological effects contribute greatly to cognitive costs of information. In Kodak, the Supreme Court treats behavior of unsophisticated consumers to be relevant insofar as it affects markets. Consumers who are prone to experience psychological switching costs could just be categorized as a subtype of unsophisticated consumers.

Furthermore, in case the European Commission is correct that loyalty rebates even put professional buyers in a weak psychological position, this should suggest that these rebates offered to consumers should a fortiori raise consumer protection concerns.

The current paper seeks to provide empirical data for the key questions whether individuals indeed stick to loyalty rebate schemes, even when switching to an outside option (a competitor's product) yields a higher expected payoff. It also intends to ascertain which factors influence the degree to which rebates create a psychological switching cost.

\section{Effects of Loyalty Rebates}

\subsection{Predictions of Rational Choice Theory}

Standard rational choice theory (RCT) predicts that rebates could lead to a suction effect (OECD, 2002; European Commission, 2009), which means that once a consumer has bought a sufficiently large quantity in the rebate scheme, it can eventually be profit-maximizing for the consumer to keep buying exclusively in the rebate scheme, because the potential rebate is so large that no competitor can make a better offer. Enforcement agencies consider that dominant incumbents can use this effect to foreclose markets for small entrant firms (OECD, 2002; European Commission, 2009). We argue that from a behaviorally informed perspective, namely from the perspective of Cumulative Prospect theory (CPT; Tversky \& Kahneman, 1992), the effect of rebates should, however, go beyond a mere suction effect.

\subsection{Predictions of Cumulative Prospect Theory}

According to CPT, rebates should induce irrational stickiness of consumers due to reference point shifts - on top of the issues already discussed in the literature. Preferences should depend on reference points, which are influenced by hopes (Thaler, 1985; Tversky \& Kahneman, 1981; Kahneman \& Tversky, 1979), goals (Heath, Larik, \& Wu, 1999), and expectations (Abeler, Falk, Götte, \& Huffmann, 2009). Buyers will hope to reach the rebate and adopt reaching the rebate threshold as their goal. Hence, they will consider a failure to reach the rebate as a loss. In the loss frame, individuals usually seek risk (Kahneman \& Tversky, 1979) and are therefore likely to prefer the risky option (i.e., stay in the rebate) over a safe outside option with equal expected value. Hence, prospect theory predicts that persons buy in loyalty 
rebate schemes longer than would be predicted by RCT. We will refer to this as the stickiness effect of rebates. Using standard parameters and assuming that the rebate payoff is adopted as the reference point, in Appendix A we formally derive from CPT with standard parameters the prediction that irrational stickiness should be observed for all rebates for which not reaching the rebate is sufficiently likely (i.e., the probability of reaching the rebate must be smaller than $76 \%$; see the fourfold pattern of risk attitudes, Tversky \& Kahneman, 1992; see also Schmidt \& Zank, 2008; Glöckner \& Pachur, 2012). Furthermore, stickiness should increase with increasing magnitude of the rebate, that is, the difference between the overall payoffs for reaching vs. not reaching the rebate. Finally, when taking into account individual differences, stickiness should increase with increasing loss aversion. ${ }^{2}$

\subsection{Previous Findings}

The predictive power of CPT for decision behavior has been supported by ample evidence using student participants (e.g., Glöckner \& Betsch, 2008; Glöckner \& Pachur, 2012; Kahneman \& Tversky, 1979; Tversky \& Kahneman, 1992), but also using representative samples of the Dutch population (Booij, Van Praag, \& Van de Kuilen, 2010) and "in the wild" (e.g., Camerer, 2005). However, some limitations have also been demonstrated: Using a critical property approach, it has, for instance, been shown that CPT cannot account for several systematic effects in three-outcome gambles (Birnbaum, 2006, 2008a, 2008b). Recent research also indicates that some effects predicted by CPT disappear in decisions from experience (e.g., Erev, Ert, \& Yechiam, 2008; Hertwig, Barron, Weber, \& Erev, 2004; Hilbig \& Glöckner, 2011). Furthermore, process analysis indicates that CPT should not be considered to be a process model for decision-making (Glöckner \& Herbold, 2011). Nevertheless, many findings, including the ones mentioned above, suggest that CPT is a reasonable paramorphic (asif) model for choices in two-outcome prospects with stated probabilities, such as the ones considered in this paper.

In contrast to the large literature on CPT, only a certain branch of marketing research has contributed specifically to empirically exploring the effect of rebates. Partly using field experiments, it was found that the closer subjects are to their rebate goal, the greater the efforts are that they take to reach it (Dreze \& Nunes 2004; Nunes \& Dreze 2006a; Kivetz, Urminsky, \& Zheng 2006), indicating additional potential to induce psychological switching costs. Further studies showed that the nature of the reward plays a role in how well the program works. Rewards that promise pleasure (luxury experience) fare better than utilitarian rewards like mon-

2 It should be noted that behavioral effects that go beyond what is captured in CPT, such as routine effects (Betsch, 2005; Betsch, Brinkmann, Fiedler, \& Breining, 1999; Betsch, Haberstroh, Glöckner, Haar, \& Fiedler, 2001), sunk cost effects (Arkes \& Blumer, 1985), or cognitive dissonance (Festinger, 1957; Shultz \& Lepper, 1996), might contribute to stickiness effects as well. We will focus our investigation on predictions by CPT, because of its prominence and because, in contrast to the other models, it is sufficiently well specified in mathematical terms to allow predicting choice behavior very accurately also on the individual level (Glöckner \& Pachur, 2012). However, we partially take into account these effects to construct strong hypotheses for a critical test of CPT. 
ey or goods the customer would have bought anyway (Nunes \& Dreze 2006b). Finally, it was shown that stating a price partly in miles and partly in money makes a loyalty program more attractive (Dreze \& Nunes 2004).

The marketing literature mainly concentrates on optimizing loyalty programs. It lacks contributions showing what the minimum rebate design is that still can impede rational switching and implement substantial psychological switching costs. Our experiment sets up a minimal rebate paradigm focusing on the very essentials. We do not use any factor, which improves the psychological attractiveness of a rebate beyond the pure conditional monetary payoff structure. Given the results from the management literature, our rebate scheme should have a hard time to seduce any participant not to maximize her expected payoffs. We pursue this minimal rebate paradigm to generate reliable evidence that indeed the mere payoff structure suffices to generate the observed effects.

The management contribution closest to our question tried to establish whether loyalty programs can increase the "share of wallet" spent on one product using a purely hypothetical survey study (Wirtz et al. 2007). From the data, the authors conclude that loyalty rebates increase perceived switching costs and that these switching costs only increase the share of wallet spent on the product if ex ante behavioral loyalty was low and the program was high-quality. Nevertheless, further research is needed to validate these claims since these interpretations of the data were partially derived post hoc, instead of being based on hypothesis testing. Furthermore, these results are difficult to integrate into a legal assessment of rebates, as "behavioral loyalty" is difficult to assess in the field and a rational comparison standard (i.e., RCT) is missing.

One sole experiment was conducted specifically to feed into the antitrust law and economics of rebates. It demonstrated non-rational attraction effects of loyalty rebates (Beckenkamp \& Maier-Rigaud, 2006). For simulated retail markets, Beckenkamp and Maier-Rigaud showed that subjects stuck to a loyalty rebate scheme as well as to a loyalty discount scheme, even if maximizing the expected payoff suggested otherwise. Although this previous work was important, it addressed relatively complex decisions in retail markets only and had some further limitations that we would like to overcome in the current study.

Regarding theory, Beckenkamp and Maier-Rigaud do not account for the mutual offsetting effects of the value function and probability weighting function of CPT when deriving their hypothesis. And in their experiment, subjects in fact had to solve a newsvendor problem (see Khouja, 1999, for a survey), which most subjects must have considered extremely difficult to do. Because subjects started out in a rebate scheme by default, they may have stayed loyal merely because they wanted to avoid any decision (including the decision to switch) in a situation they felt they did not oversee.

Our approach differs in four crucial respects from that of Beckenkamp and Maier-Rigaud. First, we focus on consumer decisions in contrast to retailer decisions; second, like many con- 
sumer environments our experimental tasks are simple, transparent, and easy to grasp and solve; third, we investigate factors possibly influencing the magnitude of the effect based on predictions of CPT; fourth, in our task consumers decided whether to enter the rebate or not so that the rebate was no default.

\section{General Method and Hypotheses}

We investigate experimentally whether stickiness can be empirically observed and whether its size can be experimentally influenced. We therefore manipulate the realization of expected demand affecting the relative attractiveness of the rebate scheme vis-à-vis an outside option. We further manipulate the magnitude of the rebate (e.g., overall $10 €$ rebate instead of $5 €$ rebate) and investigate the influence of mere buying frequency in the rebate scheme (e.g., buying 10 instead of 5 objects), while holding the differences in total payoffs (rebate magnitude) constant. We thereby stripped down the design to the very essentials of a consumer loyalty rebate scheme setting. In analogy to the abovementioned Lufthansa example, the situation we aim to capture is the following: a consumer has the possibility to enter a loyalty rebate scheme for a product he intends to buy repeatedly in a certain time period. If he reaches the target (e.g., buying 10 items), the rebate will be granted for all items bought and the overall price will be extremely low; if he does not reach the target, however, the rebate will not be granted and the price will be high. The price of the outside option is between these two prices. After some time, a random event ("external shock") decreases the likelihood that he or she can reach the target, so that it becomes rational to switch. We measure whether persons switch or stick to the rebate.

We realize this by consecutive buying decisions (rounds) concerning tokens connected by a rebate condition. Two chance moves that can lead to the omission of the critical round and of the last round represent the uncertainty about consumers' demands. The critical round is omitted with a certain probability. Options are constructed so that according to RCT people should switch to a safe outside option if the critical round is omitted. The chance move in the last round is necessary to maintain uncertainty about consumers' demand even after the consumer has learned whether the critical round takes place. We manipulate the number of repetitions (rounds) of buying and the magnitude of the rebate granted as between subjects' conditions.

In the experiment, we use rebate schemes with a sufficiently high probability for not reaching the rebate (after the critical round was omitted). As explained above, and as shown in Appendix A, CPT predicts:

Stickiness Hypothesis (H1): subjects who have consistently bought tokens up to the critical round do not exit the rebate scheme even if exit yields a higher expected payoff. 
Beyond investigating the mere existence of the stickiness effect, we were interested whether CPT can also predict its severity. We thereby constructed our material to test two further hypotheses, including manipulations for which an effect was predicted and one for which a nulleffect was predicted. The second manipulation was also selected to test an assumption underlying core arguments recently used in the regulation of rebates.

According to CPT, the stickiness effect should increase with increasing difference between the total payoffs of reaching vs. not reaching the rebates (see Appendix A). We therefore predict:

Magnitude Hypothesis (H2): A rebate of larger magnitude leads to greater stickiness.

According to CPT, the stickiness of rebates should mainly depend on magnitude, that is, the difference between high and low payoff (see Appendix A). It should not be influenced by the mere number of repetitions of previous buying. CPT therefore predicts the following nullhypothesis:

Repetition Null-Hypothesis (H3): The stickiness of rebates does not increase with the mere number of repetitions of buying if the magnitude of the rebate is constant.

Note that this is a strong null hypothesis. Previous findings indicate increased routine effects with repeated buying (Betsch, et al., 2001), which speaks against the CPT prediction. Additionally, with more repetitions subjects "invest" more money into the rebate. This may trigger a sunk cost effect (cf. Arkes \& Blumer, 1985) that also works against the specific CPT prediction. This hypothesis is also particularly interesting for practical reasons, because it captures the claim by the Court of Justice of the European Union that a longer reference period of a loyalty rebate may lead to more market foreclosure (Michelin v. Commission I. no. 82; Michelin v. Commission II. no. 85). Of course, in the situations meant by the Court of Justice of the European Union, the number of rounds and the differences between total payoffs will most likely be confounded. It is nevertheless relevant to differentiate between effects of magnitude and repetition.

\section{Experiment 1: Sticky Rebates and Indirect Comparison}

\subsection{Method}

\subsubsection{Participants and Design}

Participants were recruited from the MPI Decision Lab subject pool using ORSEE (Greiner, 2004). The majority of participants were students of the University of Bonn, from a wide variety of subject backgrounds. A total of 64 participants (mean age: 24, 37 female) took part in the 6 sessions. The study lasted between 60 and 90 minutes and participants received a per- 
formance-contingent payoff (range: $0.94 €$ to $17.80 €$; approximately USD 1.40 to 26.70$)^{3}$ in exchange for their participation. We use a 2 (negative shock on expected demand: critical round omitted vs. critical round is played) x 2 (repetition in buying: low vs. high) x 2 (rebate magnitude: low vs. high) mixed effects design. The within subject effect of the shock tests the stickiness hypothesis. The between subject effects of rebate magnitude and repetition test the hypotheses two and three respectively. While all subjects go through both demand shock conditions they are randomly assigned to one of the two repetition conditions and to one of the two magnitude conditions.

\subsubsection{Procedure}

First, participants read the experimental instructions and answered a control questionnaire (see Appendix for both) to ensure that they had understood the instructions and were able to calculate the possible payoffs. Subjects were provided with pocket calculators they could use at any time during the entire experiment. The main instructions are given in Appendix B. Payoffs in the experiment were stated in Euro. In each round of the experiment, participants could buy either a rebate token or choose an outside option. In two of the rounds (the critical and the last round), however, buying a token was only possible with a certain probability, which induced uncertainty about whether a person would reach the rebate or not. Persons were informed about the probabilities of both random events, which could turn out positive (i.e., decision between token or outside option possible) or negative (i.e., round omitted). The critical round took place with a probability of $p_{C}=.83$. The last round took place with a probability of $p_{L}=.15$. $p_{C}$ and $p_{L}$ were independent and this was common knowledge to all subjects. In order to receive the rebate for the tokens, the person needed to buy tokens in all but one round. Stated differently, the rebate was still granted if one of the random draws turned out negative and the person had bought tokens in all remaining rounds. Hence, the prior probability of reaching the rebate was high $\left(p_{R}=p_{C}+\left(1-p_{C}\right) p_{L}=.86\right)$. Nevertheless, if the critical round did not take place, this probability was reduced dramatically to $p_{R}{ }^{*}=p_{L}=.15$.

The payoffs and probabilities were set in such a way that if the critical round was omitted (for a subject who bought tokens in every previous round), RCT and CPT would make contrary predictions about staying or quitting the loyalty rebate option: the expected payoff for continuing to buy tokens was lower than that for choosing the outside option. Hence, RCT predicts rational switching to the outside option (see Table 1, second-last row). In contrast, CPT predicts a stickiness effect of rebates and continued buying of rebate token (see Table 1, last row). As the main dependent measure we used buying behavior in the round after the random draw determining whether the critical round takes place or not.

Choice data in the following round was only informative if the critical round was indeed omitted. To avoid data loss for cases in which this was not the case, we incorporated a strategy

These payoffs include the gains and losses subjects incurred when they chose and played the lotteries measuring their risk preferences and loss aversion. 
method: Prior to the realization of the random event determining whether the critical round would take place or not, subjects committed themselves to decisions in both potential states of the world, i.e., they decided what they would do if the critical round was omitted and what they would do in case it took place. If a round was omitted, it was neither possible to choose the outside option nor to buy a token. After it was randomly determined whether the critical round took place or not, the buying behavior committed to ex ante was implemented automatically. Then participants continued buying in subsequent rounds.

After subjects had gone through the experiment, we elicited risk preferences and the loss aversion parameter $\lambda$ using the incentivized scales developed by Holt and Laury (2002) and Gächter, Johnson, and Herrmann (2007). The Holt-Laury scale measures risk aversion by letting subjects choose between 10 pairs of lotteries. Each pair contains a low-risk lottery yielding $2 €$ with probability $\pi$ and $1.60 €$ with probability $1-\pi$ and a high-risk lottery yielding 3.85 $€$ and $0.10 €$ with the same probabilities $(\pi=0.1,0.2, \ldots, 1)$. The number of choices for the low-risk lottery is used as a measure for risk aversion. If, for example, a participant chooses the low risk lottery in 7 (out of the overall 10) decisions, he has a risk-aversion score of 7 (which refers to a specific range of relative risk aversion scores; see Holt \& Laury, 2002). The Gächter-Johnson-Herrmann-scale is based on six choices between playing a lottery or rejecting it. Each lottery has a fifty-fifty chance of winning $6 €$ or losing between 2 and $7 €$. For example, if the subject is not willing to play a lottery offering a 50:50 chance of winning $6 €$ and losing $3 €$, it is assumed that the person has a $\lambda>2$.

\subsubsection{Material}

In each round, participants had to decide whether to buy a token or to select an outside option while being provided with detailed information (Figure 1). The outside option was to earn $0.44 €$ per round in which it was chosen. For each token they bought, participants received $1.30 €$ at the end of the experiment. This value represented the consumption utility of the token. Dependent on condition, the buying price before the rebate was either $1.10 €$ or $1.25 €$. Hence, without a rebate, the payoff of the outside option was much higher than that of the tokens. If the rebate threshold was reached, however, the effective buying price was substantially reduced, so that then the payoff for each token was higher than the outside option. We manipulated the number of rounds in which tokens could be bought from low (10 rounds) to high (15 rounds). 
Figure 1: Information display in the decision tasks.

\section{Round 3}

You can either purchase a token or choose a direct payment.
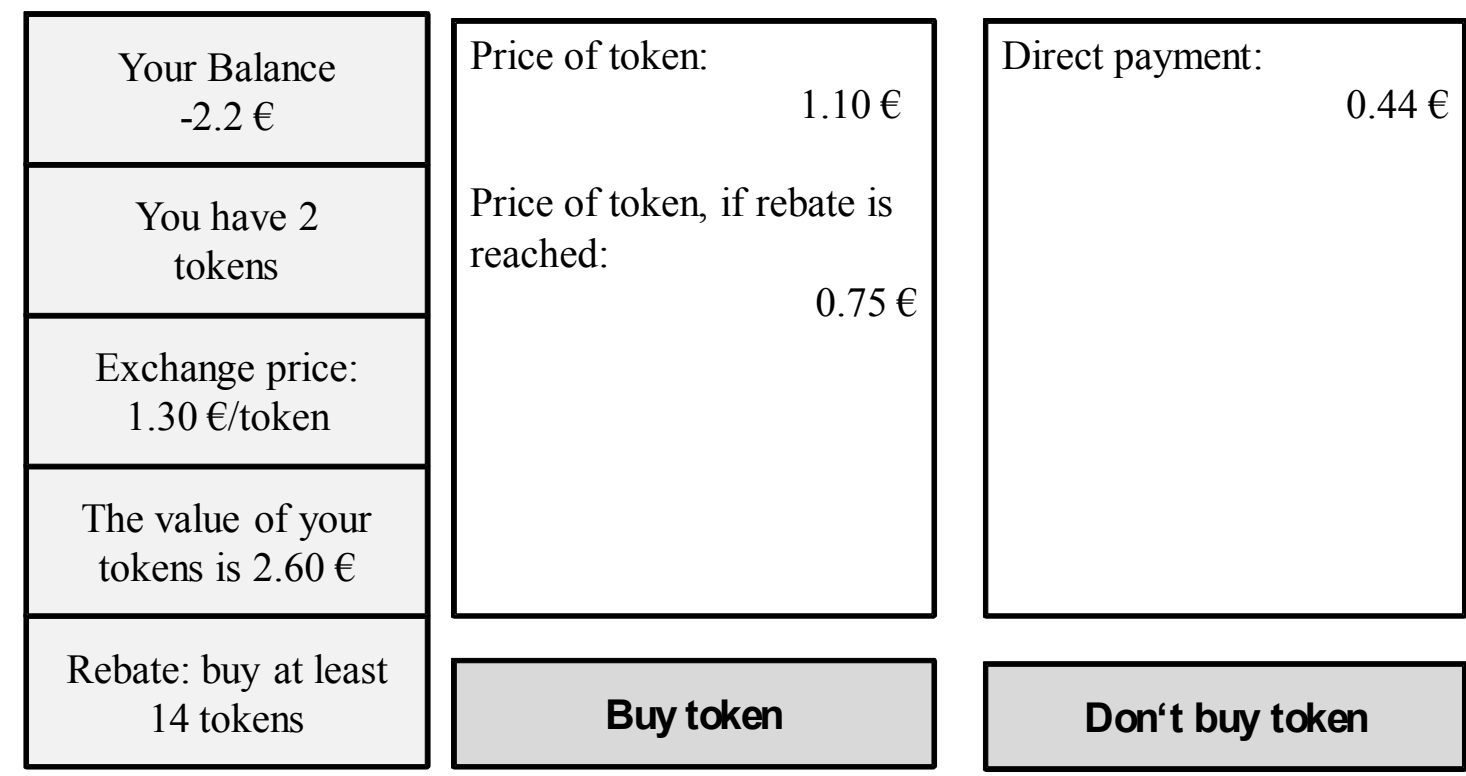

To make the results comparable between conditions, we held the incentives for leaving the rebate scheme after the first random draw, as well as the number of remaining rounds after the critical round, constant across conditions. Consequently, in the low repetition condition the critical round was Round 5, whereas it was Round 10 in the high repetition condition. Furthermore, for all conditions the difference in expected payoffs for remaining in the rebate scheme vs. quitting was held constant (except for small rounding differences). 


\begin{tabular}{|c|c|c|c|c|}
\hline & \multicolumn{4}{|c|}{ Rebate Magnitude } \\
\hline & \multicolumn{2}{|c|}{ Low } & \multicolumn{2}{|c|}{ High } \\
\hline & \multicolumn{4}{|c|}{ Repetition in Buying } \\
\hline & Low & High & Low & High \\
\hline $\begin{array}{l}\text { Rebate Magnitude in } € \text { (after criti- } \\
\text { cal round omitted) }\end{array}$ & 5.06 & 5.10 & 9.05 & 9.01 \\
\hline Repetitions in Buying (rounds) & 10 & 15 & 10 & 15 \\
\hline$x_{1}$ (price per token w/o rebate) & $1.10 €$ & $1.10 €$ & $1.25 €$ & $1.25 €$ \\
\hline$x_{2}$ (price per token with rebate) & $0.56 €$ & $0.75 €$ & $0.25 €$ & $0.61 €$ \\
\hline $\begin{array}{l}\text { Prospect of staying in rebate } \\
\text { (after critical round omitted) }\end{array}$ & $\begin{array}{c}(6.66 € ; .15 \\
1.60 €)\end{array}$ & $\begin{array}{l}(7.70 € ; .15 \\
2.60 €)\end{array}$ & $\begin{array}{l}(9.45 € \\
.15 ; .40 €)\end{array}$ & $\begin{array}{l}(9.66 € ; \\
.15 ; .65 €)\end{array}$ \\
\hline $\begin{array}{l}\text { Prospect of quitting rebate } \\
\text { option (after critical round omitted) }\end{array}$ & $\begin{array}{c}(2.56 € ; .15 \\
3.00 €)\end{array}$ & $\begin{array}{l}(4.00 € ; .15 \\
3.56 €)\end{array}$ & $\begin{array}{c}(2.40 € ; .15 \\
1.96 €)\end{array}$ & $\begin{array}{l}(2.65 € ; .15 ; \\
2.21 €)\end{array}$ \\
\hline EV for staying / quitting in $€$ & $2.36 / \underline{2.63}$ & $3.36 / \underline{3.63}$ & $1.76 / \underline{2.03}$ & $2.00 / \underline{2.28}$ \\
\hline $\begin{array}{l}\text { CPT } V \text { for staying / quitting } \\
\text { (see Appendix A) }\end{array}$ & $\underline{-6.13 /-7.53}$ & $\underline{-6.17 /-7.60}$ & $\underline{-10.22 /-13}$ & $\frac{-10.18 /-}{12.93}$ \\
\hline
\end{tabular}

Note. Prospects are given in the format (payoff 1; probability 1; payoff 2).

\subsection{Results}

Out of 64 subjects, eleven switched back and forth between the rebate and the outside option at least once before the critical round. For these subjects, both RCT and CPT predicted to leave the rebate after the critical round was omitted. Four subjects did not buy a token in round one and kept choosing the outside option consistently until the last round. This behavior of avoiding a rebate scheme can be explained by a strong aversion to risk (see Table 3 below). The remaining 49 subjects (76\%), which we will call target persons (because they are most informative for testing our hypotheses), entered the rebate scheme and started buying rebate tokens constantly until the critical round.

In line with previous findings (e.g., Holt \& Laury, 2002), our participants were mainly riskaverse with an average score of $6.03(S D=1.79)$, which corresponds to a relative risk aversion of $0.41<r<0.68$. Moreover, the Gächter-Johnson-Herrmann-scale showed that the subjects displayed loss aversion to a normal degree $(\lambda=2.18, S D=0.65$; cf. Appendix A). Four persons answered inconsistently (i.e., did not show a unique switching point, but switched back and forth between accepting and not accepting) and for them no loss-aversion score could be calculated. 


\subsubsection{Stickiness of Rebates}

Our main dependent measure was subjects' choices after the random draw determining whether the critical round took place or not. In case the critical round had taken place, for target persons it yields a higher expected payoff to buy a rebate scheme token than choosing the outside option and CPT makes the same prediction. If the critical round is omitted, however, the outside option will yield a higher expected payoff and it would be rational to switch to the outside option. CPT, by contrast, predicts sticking with the rebate. For both situations (i.e., critical round omitted or not), we coded whether persons chose the option that maximized their expected payoff (expected value / EV), that is, whether they decided in line with RCT or not.

The results indicate a stickiness effect. The proportion of EV-maximizing choices was much higher if the critical round took place as compared to being omitted (Figure 2). In line with the CPT prediction, target persons (Figure 2, left) continued to buy in the rebate even if the critical round was omitted and it was EV-maximizing to quit the rebate. The proportion of EV-maximizers, if the critical round was not omitted and RCT and CPT made the same predictions, is much higher. This difference in proportions turned out significant in a Exact McNemar test, $\chi_{d f=1}^{2}=30.00, p<.001, \mathrm{~N}=49$, and the result is robust to including all nontarget subjects into the analysis. ${ }^{4}$

Hence, we find strong support for our hypothesis H1, indicating that loyalty rebates are sticky. In accordance with the predictions of CPT, our subjects opted for the choice that yielded greater risk and lower expected payoff.

For the non-target persons (Figure 2, right), it was always rational not to buy the token, which the majority of them also did, regardless of whether the critical round was omitted or not. There was no significant difference in proportions, McNemar $\chi_{d f=1}^{2}=2.67, p=.21$.

\footnotetext{
$4 \quad$ We include them in two ways into the four-cell test matrix of the McNemar test (the four cells are: always maximize expected value; maximize if critical round is played and not if it is omitted; maximize if critical round is omitted and not if it is played; never maximize). First, we included them by their actual maximizing behavior (for them, maximizing means not buying in the rebate scheme, irrespective of whether the critical round takes place or not). Thereby most, but not necessarily all, of them end up in the always maximize cell, McNemar test, $\chi_{d f=1}^{2}=18.78, p<.0001, \mathrm{~N}=64$. Second, we also included them assuming that they had entered the rebate scheme, but counter to our CPT-Hypotheses had always maximized expected payoffs forcing all of them in the always maximize cell, McNemar test scores of $\chi_{d f=1}^{2}=$ $30.00, p<.001, \mathrm{~N}=64$.
} 
Figure 2: Choices after the critical round.

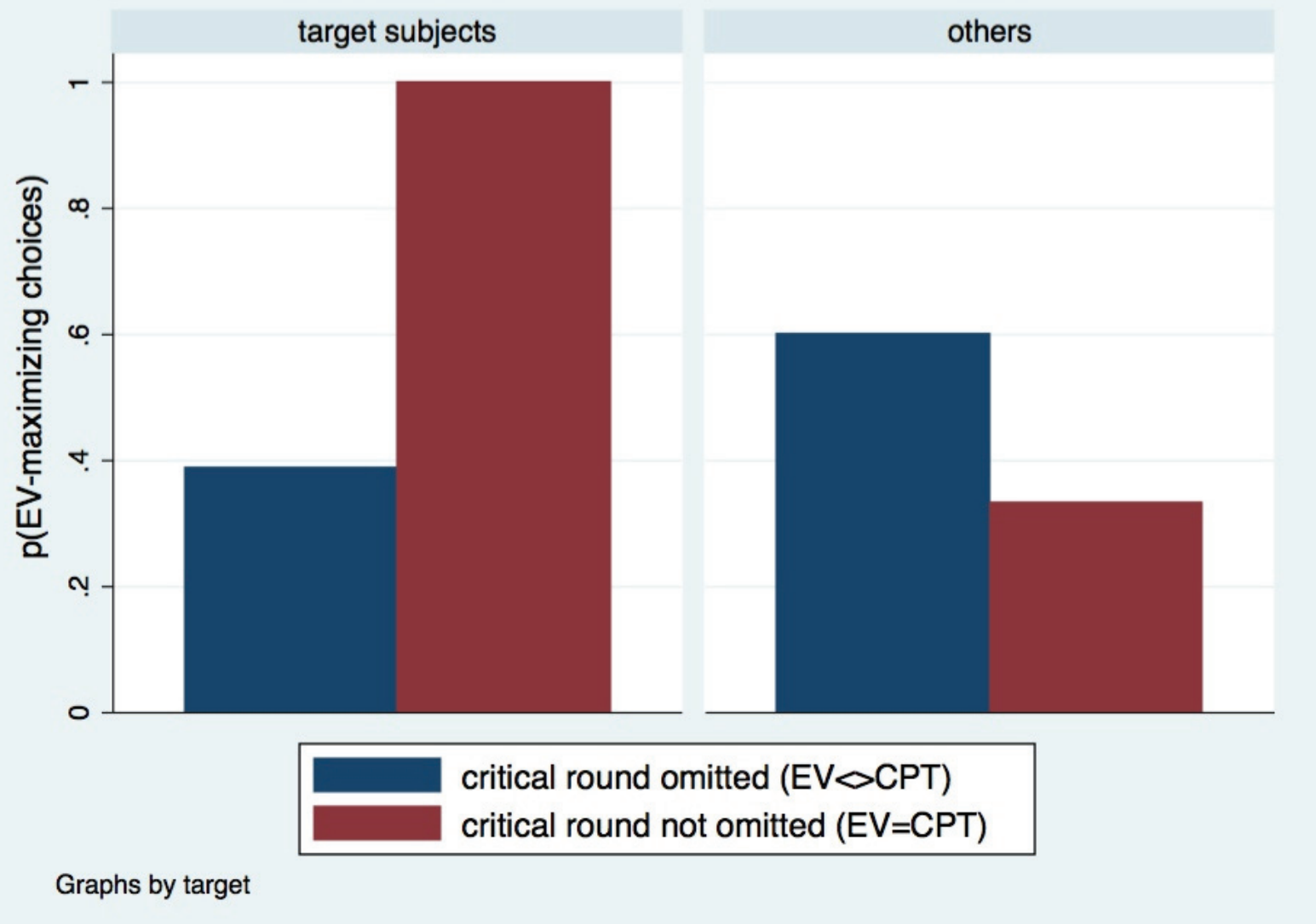

\subsubsection{Effects of Magnitude and Repetition on Stickiness}

To test our hypotheses $\mathrm{H} 2$ and $\mathrm{H} 3$, which state that stickiness increases with magnitude of the rebate, but not with mere repetition in buying, we analyzed choice behavior in the critical round separately for the four conditions, considering the target persons only (Figure 3). The stickiness effect was found in three of four conditions at a conventional and in one condition at a marginal level of significance (low magnitude \& low repetition: Exact McNemar $\chi_{d f=1 ; \mathrm{N}=16}^{2}=9.00, \mathrm{p}=.004$; high magnitude \& low repetition: Exact McNemar $\chi_{d f=1 ; \mathrm{N}=8}^{2}=5.00$, $\mathrm{p}=.062$; low magnitude \& high repetition: Exact McNemar $\chi_{d f=1 ; \mathrm{N}=11}^{2}=10.0, \mathrm{p}=.002$; high magnitude \& high repetition: Exact McNemar $\left.\chi_{d f=1 ; \mathrm{N}=14}^{2}=8.00, \mathrm{p}=.008\right)$. All results are robust to including the non-target subjects under the assumption they had maximized EV if they had entered the rebate scheme consistently. Including the non-target subjects according to their actual maximizing behavior leads to insignificant results in the high magnitude \& low repetition condition and renders results in the low magnitude $\&$ high repetition condition marginally significant (see footnote 4 , above). 
Figure 3: Choices after the critical round by condition.

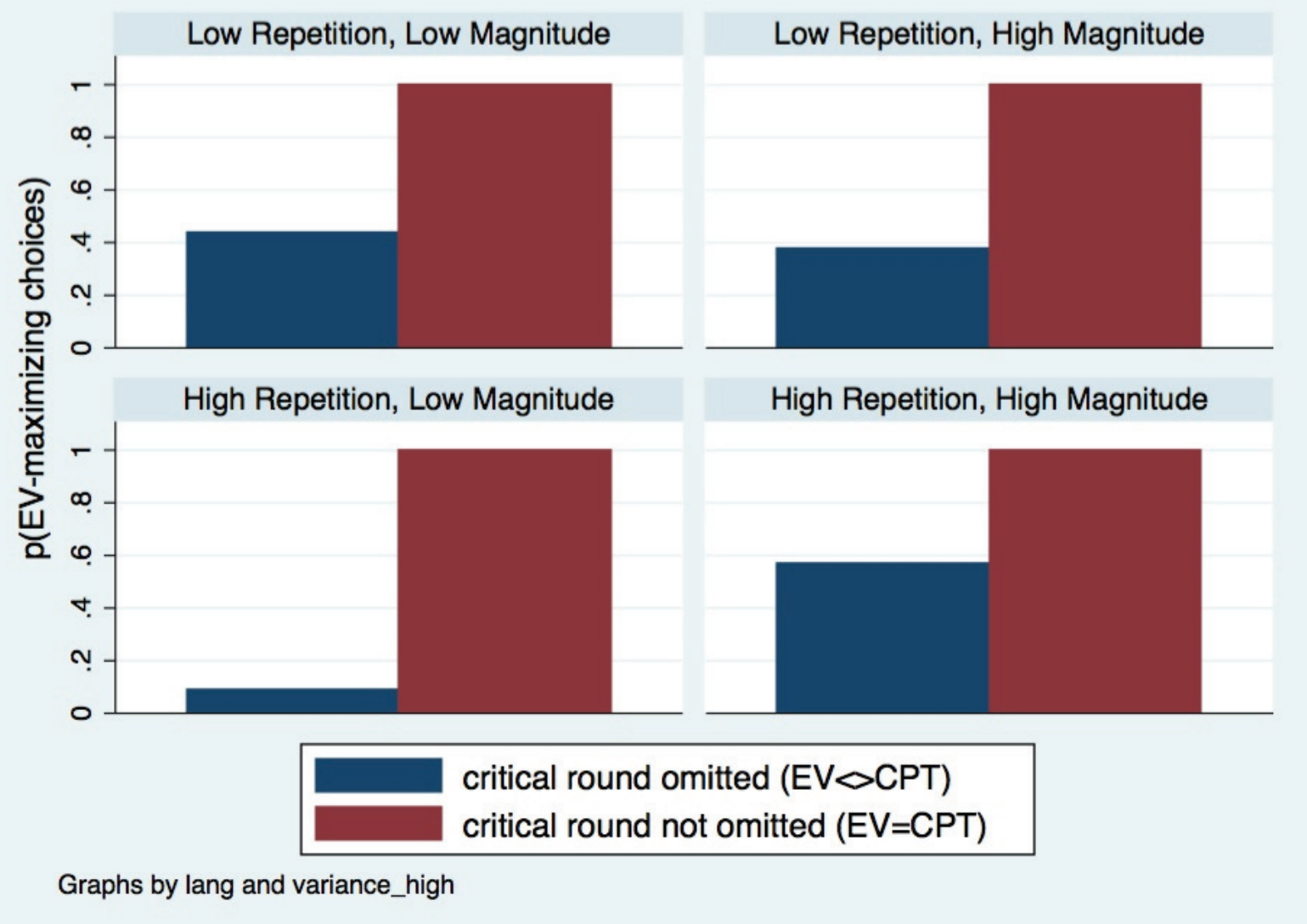

For a regression-based analysis, we generated a sticky-buying score. The score was set to 1 if the person bought the token after the critical round was omitted and 0 otherwise. The score hence indicated whether persons performed sticky-buying (1) or not (0). We conducted a logistic regression ${ }^{5}$ with this sticky-buying score as dependent variable and the two condition variables and their interaction as predictors and risk aversion, loss aversion, and gender as further control variables (Table 2).

5 We estimated the equation $Y=\beta_{0}+\beta_{1} X_{1}+\ldots+\beta_{n} X_{n}+\varepsilon$ with logit. A value of $Y=1$ indicated the decision to keep buying in the rebate scheme, $\mathrm{Y}=0$ indicated the decision not to buy in the rebate scheme. The variables $\mathrm{X}_{1}$ to $\mathrm{X}_{7}$ are the variables and interactions listed in the regression Table 2 . 
Table 2: Three Logistic Regression Models Predicting Stickiness.

\begin{tabular}{lccc}
\hline & $(1)$ & $(2)$ & $(3)$ \\
& Sticky-Buying & Sticky-Buying & Sticky-Buying \\
\hline Repetition high & 0.772 & 1.142 & 1.141 \\
(0-no, 1-yes; centered) & $(1.01)$ & $(1.39)$ & $(1.19)$ \\
Magnitude High & -1.194 & $-1.413+$ & $-1.955^{*}$ \\
(0-no, 1-yes; centered) & $(-1.59)$ & $(-1.77)$ & $(-2.06)$ \\
& & & $-3.196+$ \\
IE Repetition*Magn. & $-2.850+$ & $-3.356^{*}$ & $(-1.79)$ \\
& $(-1.91)$ & $(-2.07)$ & $-2.051^{*}$ \\
Gender & & & $(-2.53)$ \\
(0-female, 1-male) & & $-1.576^{*}$ & \\
Risk Aversion Score & & $(-2.28)$ & 0.280 \\
(0-10) & & & $(0.79)$ \\
Loss Aversion $(\lambda)$ & & & -0.522 \\
Constant & & & $(-0.81)$ \\
& & & 1.273 \\
Observations & & & $(0.58)$ \\
\hline
\end{tabular}

Note. Raw coefficients for a logistic regression on sticky-buying (buying choices after the critical round, i.e., when round 5 or 10 was omitted). Buying indicates stickiness preventing subjects from maximizing expected payoffs. $z$-statistics in parentheses. Robust standard errors were used. Model 3 includes four observations less due to missing loss-aversion scores. ${ }^{+} p<0.10,{ }^{*} p<0.05,{ }^{* *} p<0.01,{ }^{* * *} p<0.001$.

We find a significant effect of our magnitude manipulation on stickiness. In contrast to the magnitude hypothesis $\mathrm{H} 2$, however, stickiness decreases with increasing magnitude of the rebate (see Figure 3) and $\mathrm{H} 2$ has to be rejected. There was no significant effect of repetition on stickiness that allows maintaining the null-hypothesis H3. However, it has to be taken into account that the power of the analysis was relatively low $(1-\beta=.56$; assuming: odds-ratio $=$ 2, $\mathrm{p}(\mathrm{Y}=1 \mid \mathrm{X}=1)_{\mathrm{H} 0}=.5$; two-sided test) (Faul, Erdfelder, Lang, \& Buchner, 2007).

We also find a (marginally) significant interaction effect of magnitude and repetition, which was not predicted by CPT. High magnitude combined with high repetition frequency decreased the stickiness of a rebate and led to considerably more rational buying behavior.

Additionally, we find a significant gender effect. Female subjects were more inclined to stick to the rebate than male subjects, once they had entered the rebate scheme. Risk aversion and 
loss aversion had no effect on stickiness (after the person entered the rebate), although CPT predicts that increasing loss aversion should lead to higher stickiness (see Appendix A).

\subsubsection{Individual Differences in Entering the Rebate}

We were further interested in the question whether there were individual differences in entering the rebate scheme in the first place, dependent on people's risk aversion and loss aversion. One might expect more risk-averse and loss-averse persons to avoid entering rebate schemes already in the first place. As mentioned above, the large majority of persons entered the rebate scheme and bought in it until the critical round $(\mathrm{N}=49)$, but there was also a minority of persons who avoided the rebate altogether and chose the outside option from the beginning $(\mathrm{N}=4)$. We found higher risk aversion in these rebate avoiders $(\mathrm{M}=7.2, \mathrm{SE}=1.18)$ compared to target persons $(\mathrm{M}=5.8, \mathrm{SE}=0.17)$, which was marginally significant in a nonparametric test (Mann-Whitney: $p=.07$; one-sided). Similarly, rebate avoiders had higher loss aversion $(\mathrm{M}=2.47, \mathrm{SE}=0.53)$ compared to target persons $(\mathrm{M}=2.17, \mathrm{SE}=0.08)$, which was also marginally significant (Mann-Whitney: $p=.08$; one-sided).

\subsection{Discussion}

As expected, we show that loyalty rebates lead to irrational stickiness, in that consumers do not switch to outside options with higher payoff. We did not find support for the magnitude hypothesis and there was no significant effect of repetition on stickiness that allows remaining the repetition null-hypothesis in line with CPT. We also found an unexpected interaction of repetition and magnitude of the rebate.

One of the potential weaknesses of the first experiment is that we show the stickiness effect only as indirect comparison between a situation in which a critical round was omitted or not without controlling for other differences between these situations. To rule out this issue and to test the stability of the observed effects, we conducted a second experiment.

\section{Experiment 2: Sticky Rebates in Direct Comparisons with Gambles}

\subsection{Method}

Participants were mainly students from the University Bonn, again recruited from the MPI Decision Lab subject pool using ORSEE (Greiner, 2004). A total of 68 participants (mean age: $24.9,37$ female) took part in the experiment. The study lasted between 60 and 90 minutes and participants received a performance-contingent payoff (range: $0 €$ to $29.69 €$; approximately USD 41.27) in exchange for their participation. Procedure and design were essentially the same as in Experiment 1, except that participants did additionally choose between risky 
and safe lotteries, which were equivalent to the prospects that were involved in their sticky buying decision. That is, they explicitly decided between the lotteries presented in Table 1 , row 5 vs. row 6 . Both the rebate scheme and the lottery ticket were played and paid. This allows for a direct evaluation of the stickiness effect of rebates because according to CPT for lotteries no shift in reference point should occur. ${ }^{6}$

\subsection{Results}

Again, the large majority of participants (i.e., $N=54, p=.79$ ) entered the rebate scheme and started buying rebate tokens constantly until the critical round. For these target persons, we replicate the stickiness effect, in that the proportion of EV-maximizing choices was much higher if the critical round took place ( $p=.96$ ), as compared to being omitted $(p=.56)$, Exact McNemar $\chi_{d f=1}^{2}=22.00, p<.001, \mathrm{~N}=54$. Again, this result is robust to the inclusion of the non-target subjects. ${ }^{7}$ More importantly, we also find the stickiness effect in a direct comparison between persons' behavior in the rebate scheme and in choosing between equivalent lotteries. In equivalent choices mimicking the situation after the critical round was omitted, target persons choose the EV-maximizing, safe outside option in the lotteries $(p=.72)$ significantly more often than when buying in the loyalty rebate ( $p=.56$; see above), McNemar $\chi_{d f=1}^{2}$ $=4.26, p=.039, \mathrm{~N}=54$. This effect only proves robust to the inclusion of non-target subjects under the assumption that they would have always maximized if they had entered the rebate, McNemar $\chi_{d f=1}^{2}=4.26, p=.039, \mathrm{~N}=68$.

The significant decrease of stickiness with magnitude and the interaction of magnitude and repetition could both not be replicated in a logistic regression that was conducted with the same predictors as before (cf. model 3; Table 2). However, the coefficients are in the same direction as observed in Experiment 1 (magnitude: $b=-.45, z=-0.76, p=0.45$; IE magnitude $\mathrm{x}$ repetition: $b=-.50, z=-0.40, p=0.69)$. The effect of gender on stickiness did not replicate either ( $b=.41, z=0.70, p=0.48)$. Also, the differences in risk aversion and loss aversion between rebate avoiders $(n=4)$ and target persons could not be replicated, but were both in the previously observed direction (Mann-Whitney: for risk aversion $p=.48$; for loss aversion $p=$ .13; one-sided).

\footnotetext{
$6 \quad$ Models of expectation based reference points (Köszegi \& Rabin, 2006) may also not predict a reference point shift by the lottery, because they assume that reference points are based on lagged expectations. But in our setting subjects chose immediately after they were presented with the choice between the two lotteries tickets.

$7 \quad$ McNemar $\chi_{d f=1}^{2}=16.67, p<.001, \mathrm{~N}=68$ if they are included with their actual maximizing behavior; McNemar $\chi_{d f=1}^{2}=22.00, p<.001, \mathrm{~N}=68$, if they are included under the assumption that they had always maximized had they entered the rebate scheme
} 


\subsection{Discussion}

In the second study, we replicate the stickiness effect observed in Experiment 1 and also show that it can be found when directly comparing choices in loyalty rebate schemes with choices between equivalent lotteries. The second experiment is also informative concerning the stability of the other observed effects concerning the factors influencing the magnitude of stickiness and whether persons enter rebate schemes or not. The effects of these factors seem to be relatively weak and potentially unstable and should be interpreted with caution.

A classic argument in economics is that biases and irrationality in choice behavior should disappear in repeated market interactions. According to this view, loyalty rebates might be unproblematic because consumers will learn over time that they are detrimental and avoid them further on. We investigated this possibility and the stability of the stickiness effect in a third experiment.

\section{Experiment 3: Stickiness in Repeated Rebate Scenarios}

In the third experiment, participants could decide whether or not to buy in rebate schemes in eight different scenarios. Each of them consisted of ten buying trials. As in the real world, the scenarios differed concerning conditions of the rebates on the goodness of alternative options. To mimic a common situation in reality, we induced uncertainty concerning the alternative option. That is, when making the decision whether or not to enter a loyalty rebate scheme, no information was provided whether an alternative option available later on would be good or bad. Half of the scenarios resembled situations as above, in which switching to an outside option was rational (switching scenarios), but stickiness should lead to continued buying. The other half were controls in which the alternative option appearing later on was bad and it was therefore money-maximizing to continue buying in the rebate scheme (non-switching scenarios).

\subsection{Method}

Participants were again mainly students from the University Bonn recruited from the MPI Decision Lab subject pool using ORSEE (Greiner, 2004). A total of 43 participants (mean age: 24.6, 22 female) took part in the third experiment, which lasted about 90 minutes. Participants received a performance-contingent payoff (range: $2.34 €$ to $19.54 €$; approximately USD 3.25 to USD 27.16) in exchange for their participation. The scenarios were manipulated within subjects according to a 2 (switching vs. non-switching scenarios) x 4 (versions) design. Presentation order was counterbalanced between subjects (i.e., eight different orders determined by Latin squares). 
The procedure within each scenario was similar to that in the previous experiments, except that we tried to increase external validity in some respects. For 10 rounds, participants could buy the loyalty rebate option A, but rounds 5 to 10 could all be omitted with a certain probability (e.g., each one of the planned buys could be cancelled). The loyalty rebate was granted if option A had been bought a certain number of times (i.e., 7 or 9 out of 10 times). It was common knowledge that an alternative option B (e.g., competing flight offer) would be available later on - but people had no knowledge concerning the specificities of this option until then. In each round, persons had the option to "do nothing", which was connected with a small cost. In the four switching scenarios, outcomes were constructed so that quitting the rebate scheme and changing to option B was EV-maximizing. Continued buying in the rebate, in contrast indicates stickiness. In the non-switching control scenarios, continued buying was rational. We measured stickiness by the number of buying decisions for the loyalty rebate option $\mathrm{A}$ in the round after option $\mathrm{B}$ became available. After reading the instructions, all persons worked on a test scenario to assure understanding.

\subsection{Results and Discussion}

In the majority of scenarios, participants started buying consistently in the rebate scheme $(p=$ .64). Analyses were conducted for these cases only. In the switching scenarios, we found a strong stickiness effect. In the round after option B became available, almost two thirds of the persons who had entered the rebate scheme showed irrational buying behavior and continued buying option A in the rebate scheme $(p=.63, S E=.049) .{ }^{8} \mathrm{~A}$ similar proportion of continued rational buying option A was observed in the non-switching scenarios $(p=.65, S E=.068)$. A Wald test revealed that both proportions did not differ significantly, $F(1,42)=0.15, p=0.70$. This indicates a strong stickiness effect, and indicates that after entering a rebate scheme, consumer decisions seem to be rather uninfluenced by the payoff of the outside option available later on. This irrationality, of course, can lead to substantial financial loss.

Stickiness did not disappear after repeated buying in rebate schemes. Even in the switching scenario presented at the last position, we observed a majority of irrational buying ( $p=.60$, $S E=.16$ ). Stickiness of loyalty rebates did not reduce with increasing experience, as indicated by a logistic regression predicting irrational buying by presentation order, $b=.06, z=0.68, p$ $=0.498$. Hence, in the third experiment, we show the stability of the stickiness effect of loyalty rebates and find no support for the hypothesis that irrationality reduces with experience.

8 This and all following SEs are cluster corrected to account for the repeated measurement design (Rogers, 1993). 


\section{General Discussion}

Psychological switching cost induced by loyalty rebates is an important topic for antitrust law and consumer protection law. However, there was a lack of empirical data investigating the effects of such rebates on consumers. Most arguments concerning regulation rested on the assumption of buyers who maximize expected surplus. In this paper, we show that loyalty rebates impede rational switching of consumers, thereby inducing a psychological switching cost we call stickiness effect.

We report results from three experiments that investigate loyalty rebates in comprehensive tasks mirroring the particularities of consumer purchases. We used Cumulative Prospect Theory (CPT) to derive predictions concerning buying behavior in rebates.

The core finding of this paper is that, in line with CPT predictions, loyalty rebates induce a stickiness effect in that they impede customers' switching from the rebate product to better (payoff-maximizing) outside options. Therefore, loyalty rebates have an underestimated potential to be used as a means for inefficient market foreclosure and to harm consumers. The stickiness effect seems to be strong and led between roughly half and two third of the (target) persons to choose the option with the lower expected value. The stickiness effect seems to be very robust and it does not reduce with a medium degree of repeated exposure (i.e., over eight times).

\subsection{Further findings}

As a side aspect, we also investigated the influence of rebate magnitude and buying repetition on the size of the stickiness effect. Overall, the effects of rebate magnitude and buying repetition seem to be a bit unstable. In the first experiment, stickiness significantly decreases with increasing magnitude of the rebate, although CPT predicts the opposite effect. However, the effect could not be replicated in the second study. A null-effect of repetition on stickiness observed in both Experiments 1 and 2 was in line with CPT predictions. Note, however, that the latter cannot be considered clear evidence in favor of the theory because the power of the analysis was relatively low. Furthermore, we found in both studies that people's loss aversion had no effect on stickiness. CPT would have predicted a positive relation. A gender effect that was observed in Experiment 1 - as female participants showed a higher stickiness to rebates (even when controlling for differences in risk aversion and loss aversion) — could also not be replicated in a second study. Finally, in the first experiment, we found that individual differences could influence people's willingness to enter rebate schemes in the first place. Rebate avoiders seem to be more risk-averse and loss-averse, compared to persons entering a rebate scheme. We observe a similar tendency in Experiment 2, which was, however, not significant either. Further research is needed to test these effects. 


\subsection{Implications for the Regulation of Loyalty Rebates}

The first and most important implication is that loyalty rebates induce a stickiness effect in consumers. Rebates generate a non-rational psychological switching cost. A model that assumes agents to maximize expected payoffs is not well suited to predict the effects of loyalty rebates on consumers. The psychological switching costs increase the potential of loyalty rebates to inflict substantial harm on consumers because consumers will end up with less rent on average than they would end up with in the absence of the rebate scheme. The psychological switching costs may also increase the potential of loyalty rebates to foreclose consumer markets to entrants: the entrant has to compensate the additional attraction of rebates that we call stickiness by selling his product even more cheaply than he would do otherwise. In case a pre-existing asymmetry in the market guarantees a dominant firm to be the default provider for most customers, it can (ab)use the psychological switching costs of a rebate scheme to foreclose the market inefficiently to competitors and entrants. The stickiness effect we find therefore provides an argument to treat rebates more restrictively both under antitrust law and under consumer protection law.

We found no support for the Court of Justice of the European Union's opinion that a longer reference period that would induce increased repetitions in buying increases the potential for market foreclosure. There was no effect on stickiness with regard to the instances of buying repetitions.

We think our results can cautiously be extended to professional buyers - bearing in mind the problems of external validity arising when extrapolation results from lab experiments to firm behavior. Our experimental task shares some features with buying in rebate schemes in markets with professional buyers. Therefore our findings provide converging evidence for the results by Beckenkamp and Maier-Rigaud (2006), who explicitly deal with professional buyers. The problems of external validity certainly are smallest when retail units are small and individuals take the relevant decisions. Here our results are likely to apply to professional buyers as well. Indeed, in the Michelin cases, the dominant firm Michelin sold to retailers apparently including a significant number of small car repair shops. Here, our findings could well apply. So, all in all, the Commission appears to be right not to have ignored the psychological state of (retailing) buyers in its decision.

\subsection{Implications for Modeling Choice Behavior for Loyalty Rebates}

The stickiness effect predicted by CPT (with the additional assumption that reference points are shifted to the rebate payoff) was clearly supported by the data. However, we also find that the partially reversed effect of rebate magnitude, the sometimes observed interaction between magnitude and repetition, and the null effect for loss aversion on stickiness cannot be easily explained by CPT. Hence, although CPT explains the data better than rational-choice theory, there is a need for further refinements and rebate-specific extensions in order to develop a 
more comprehensive model for buying decisions in rebate environments, namely one that fully accounts for our findings.

\section{Conclusions}

Overall, we conclude that loyalty rebates lead to irrational buying behavior, amounting to an additional psychological switching cost that can cause substantial financial losses for consumers. This effect increases the potential of loyalty rebates to be used as a tool to foreclose markets and provides an argument for a more restrictive position towards loyalty rebates under consumer protection law. Previous arguments and rulings concerning the regulation of loyalty rebates under antitrust law both in the EU and in the US were mainly based on the assumption of rational buying. Stickiness effects add to these existing problems. Therefore the potential danger of loyalty rebates has been underestimated. The demonstrated stickiness effect backs the role psychological effects already play in European antitrust law today. It generally supports the greater scrutiny loyalty rebates have recently been subject to both in the EU and the US. 


\section{References}

Abeler, J., Falk, A., Götte, L., \& Huffman, D. (2009). Reference points and effort provision. Working Paper Series Institute for the Study of Labor (IZA).

Arkes, H. R. \& Blumer, C. (1985). Psychology of Sunk Cost. Organizational Behavior and Human Decision Processes, 35, 124-140.

Beckenkamp, M. \& Maier-Rigaud, F. (2006). An experimental investigation of article 82 EC rebate schemes. The Competition Law Review, 2, 1-29.

Betsch, T., Haberstroh, S., Glöckner, A., Haar, T., \& Fiedler, K. (2001). The effects of routine strength on adaptation and information search in recurrent decision making. Organizational Behavior and Human Decision Processes, 84, 23-53.

Birnbaum, M. H. (2006). Evidence against Prospect Theories in gambles with positive, negative, and mixed consequences. Journal of Economic Psychology, 27, 737-761.

Birnbaum, M. H. (2008a). New paradoxes of risky decision making. Psychological Review, $115,463-501$.

Birnbaum, M. H. (2008b). New tests of cumulative prospect theory and the priority heuristic: Probability-outcome tradeoff with branch splitting. Judgment and Decision Making, 3, 304-316.

Booij, A. S., Van Praag, B. M. S., \& Van de Kuilen, G. (2010). A parametric analysis of prospect theory's functionals for the general population. Theory and Decision, 68, 115-148.

Camerer, C. F. (2005). Prospect theory in the wild: Evidence from the field. In M. H. Bazerman (Ed.), Negotiation, decision making and conflict management (Vol. 1-3, pp. 575588). Northampton, MA: Edward Elgar Publishing.

Directorate General Competition (2005). Discussion Paper on the Application of Article 82 of the Treaty to Exclusionary Abuses, Brussels, available at http://ec.europa.eu/comm/competition/antitrust/art82/discpaper2005.pdf

Dreze, X., Nunes J. C. (2011). Recurring Goals and Learning: The Impact of Successful Reward Attainment on Purchase Behavior. Journal of Marketing Research, 48, 268-281.

Dreze, X., Nunes, J. C. (2004). Using Combined-Currency Prices to Lower Consumers' Percieved Cost. Journal of Marketing Research, 41, 59-72.

European Commission (2009). Guidance on the commission's enforcement priorities in applying article 82 of the EC treaty to abusive exclusionary conduct by dominant undertakings, available at: http://ec.europa.eu/competition/antitrust/art82/guidance_en.pdf 
Erev, I., Ert, E., \& Yechiam, E. (2008). Loss aversion, diminishing sensitivity, and the effect of experience on repeated decisions. Journal of Behavioral Decision Making, 21, 575597.

Faul, F., Erdfelder, E., Lang, A.-G., \& Buchner, A. (2007). G*Power 3: A flexible statistical power analysis program for the social, behavioral, and biomedical sciences. Behavior Research Methods, 39, 175-191.

Festinger, L. (1957). A theory of cognitive dissonance. Stanford, CA: Stanford University Press.

Gächter, S., Johnson, E. J. \& Herrmann, A. (2007). Individual-level loss aversion in riskless and risky choices. CeDEx Discussion Paper No. 2007-02.

Glöckner, A., \& Betsch, T. (2008). Do people make decisions under risk based on ignorance? An empirical test of the Priority Heuristic against Cumulative Prospect Theory. Organizational Behavior and Human Decision Processes, 107, 75-95.

Glöckner, A., \& Herbold, A.-K. (2011). An eye-tracking study on information processing in risky decisions: Evidence for compensatory strategies based on automatic processes. Journal of Behavioral Decision Making, 24, 71-98.

Glöckner, A., \& Pachur, T. (2012). Cognitive models of risky choice: Parameter stability and predictive accuracy of Prospect Theory. Cognition, 123, 21-32.

Greiner, B. (2004). An online recruitment system for economic experiments. In K. Kremer \& V. Macho (Eds.), Forschung und wissenschaftliches Rechnen 2003. GWDG Bericht 63 (pp. 79-93). Göttingen: Ges. für Wiss. Datenverarbeitung.

Heath, C., Larrick, R. P., Wu, G. (1999). Goals as reference points. Cognitive Psychology, 38, 79-109

Hertwig, R., Barron, G., Weber, E. U., \& Erev, I. (2004). Decisions from experience and the effect of rare events in risky choice. Psychological Science, 15, 534-539.

Hilbig, B. E., \& Glöckner, A. (2011). Yes, they can! Appropriate weighting of small probabilities as a function of information acquisition. Acta Psychologica, 138, 390-396.

Holt, C. A. \& Laury, S. K. (2002). Risk aversion and incentive effects. The American Economic Review, 92, 1644-1655.

Huck, S., Zhou, J., Duke, C. (2011), Consumer Behavioral Biases in Competition - A Survey, report to the Office of Fair Trading, http://www.oft.gov.uk/shared_oft/research/OFT1324.pdf 
Kahneman, D., \& Tversky, A. (1979). Prospect theory: An analysis of decision under risk. Econometrica, 47, 263-292.

Khouja, M. (1999). The single period (news vendor) problem: literature review and suggestions for future research, Omega, International Management Science, 27, 537-553.

Kivetz, R., Urminsky, O., Zheng, Y. (2006). The Goal-Gradient Hyothesis Resurrected: Purchase Acceleration, Illusionary Goal Progress, and Consumer Retention. Journal of Marketing Research, 43, 39-58.

Koehler, D. J., Brenner, L., \& Griffin, D. (2002). The calibration of expert judgment: Heuristics and biases beyond the laboratory. In T. Gilovich, D. Griffin \& D. Kahneman (Eds.), Heuristics and biases: The psychology of intuitive judgment (pp. 686-715). New York, NY: Cambridge University Press.

Köszegi, B, Rabin, M. (2006). A model of reference dependent preferences. The Quaterly Journal of Economics 121 (4), 1133-1165.

Lederman, M (2007). Do enhancements to loyalty programs affect demand? The impact of international frequent flyer partnerschips on domestic airline demand. RAND Journal of Economics 38 (4), 1134-1158

Nunes, J. C., Dreze, X. (2006a). The Endowed Progress Effect: How Artificial Advancement Increases Effort. Journal of Consumer Research, 32, 504-512.

Nunes, J. C., Dreze, X. (2006b). Your Loyalty Program is Betraying You. Harvard Business Review, April, 124-131.

Rabin, M. (1998). Psychology and economics. Journal of Economic Literature, 36, 11-46

Reeves, A. P., Stucke, M. E. (2011). Behavioral Antitrust. Indiana Law Journal, 86, 15271586.

Rosch, J. T. (2010). Behavioral Economics: Observations Regarding Issues That Lie Ahead. Speach delivered at Vienna Competition Conference, Vienna, Austria, June 9, 2010. Available at: http://www.ftc.gov/speeches/rosch/100609viennaremarks.pdf

Schmidt, U., Starmer, C., \& Sugden, R. (2008). Third-generation prospect theory. Journal of Risk and Uncertainty, 36, 203-223.

Schmidt, U., \& Zank, H. (2008). Risk aversion in cumulative prospect theory. Management Science, 54, 208-216.

Shultz, T. R., \& Lepper, M. R. (1996). Cognitive dissonance reduction as constraint satisfaction. Psychological Review, 103, 219-240. 
Stott, H. (2006). Cumulative prospect theory's functional menagerie. Journal of Risk and Uncertainty, 32, 101-130.

Stucke, M.E. (2007). Behavioral Economics at the Gate: Antitrust in the Twenty-First Century. Loyola University Chicago Law Journal, 38, 513-519.

Thaler, R. (1980). Toward a positive theory of consumer choice. Journal of Economic Behavior \& Organization, 1, 39-60.

Thaler, R. (1985). Mental accounting and consumer choice. Marketing Sciences, 4, 199-214.

Tor, A., Rinner W. J. (2011). Behavioral Antitrust: A New Approach to the Rule of Reason after Leegin. University of Illinois Law Review, 805-864.

Tor, A., (2002). The Faible of Entry. The Michigan Law Review, 101, 482-567.

Tversky, A., \& Kahneman, D. (1974). Judgment under uncertainty: Heuristics and biases. Science, $185,1124-1131$.

Tversky, A. \& Kahneman, D. (1981). The framing of decisions and the psychology of choice. Science, 211, 453-458.

Tversky, A., \& Kahneman, D. (1992). Advances in prospect theory: Cumulative representation of uncertainty. Journal of Risk and Uncertainty, 5, 297-323.

Werden, G. J., Froeb, L. M., Shor, M. (2011). Behavioral Antitrust and Merger Control. Journal of Institutional and Theoretical Economics, 167, 126-142.

Wirtz, J., Mattila A.S., Lwin, A. O. (2007). How Effective are Loyalty Reward Programs in Driving Share of Wallet? Journal of Service Research, 9, 327-334. 


\subsection{Cases}

CJEU, Case 322/81 Michelin v. Commission I [1983] ECR 3461.

CJEU, Case 85/76 Hoffmann-LaRoche v. Commission [1979] ECR 461.

CJEU, Case C-95/04 British Airways v. Commission [2007] ECR I-2331

GC, Case T-203/01 Michelin v. Commission II [2003] ECR II-4071.

GC, Case T-155/06 Tomra v. Commission [2010] ECR II-000

Commission, Case COMP/C-3/37.990 Intel v. Commission [2009] OJ C 227/07, p. 13-17.

Commission, Case COMP/E-2/36.041/PO Michelin v Commission II [2002] OJ L 143/1.

FTC v. R.F. Keppel \& Bro., Inc., 291 U.S. 304 (1934).

Eastman Kodak Co. v. Image Technical Services, Inc. et al. 504 U.S. 451 (1992).

Concord Boat Corp. v. Brunswick Corp., 207 F.3d 1039 (8th Cir.), cert. denied, 531 U.S. 979 (2000).

LePage's Inc v. 3M (Minnesota Mining and Manufacturing Co), 324 F3d 141 (3d Cir 2003) (en banc), cert. denied 124 S Ct 2932 (2004).

ZF Meritor, LLC v. Eaton Corp., $3^{\text {rd }}$ Circuit, yet unpublished (2012). 


\section{Appendices}

\subsection{Appendix A}

Let $\mathrm{x}_{1}$ and $\mathrm{x}_{2}$ be the possible monetary outcomes (payoffs) for a prospect and assume $\mathrm{p}_{1}$ and $1-p_{1}$ to be the probabilities that the respective outcomes realize. The expected value for this prospect is given by:

$$
E V=p_{1} x_{1}+\left(1-p_{1}\right) x_{2}
$$

and, according to rational choice theory, persons should be indifferent between this prospect and any equivalent cash amount $\mathrm{c}$ :

$c=E V$.

According to CPT, the value $V$ of a prospect with outcomes $x_{1} \leq \ldots \leq x_{k} \leq 0 \leq x_{k+1} \leq \ldots \leq x_{n}$ is given by:

$V=\sum_{i=1}^{k} \pi_{i}^{-} v\left(x_{i}\right)+\sum_{j=k+1}^{n} \pi_{j}^{+} v\left(x_{j}\right)$

with $v$ as continuous and strictly increasing utility function satisfying $v(0)=0$, and $\pi^{+}$and $\pi^{-}$ as decision weights, for gains and losses respectively. Decision weights result from rankdependent transformation of the outcome probabilities, considering gains and losses separately. This means that the same probability can result in different decision weights, dependent on whether it belongs to a high or a low outcome. Decision weights are defined by:

$\pi_{1}^{-}=w^{-}\left(p_{1}\right)$

$\pi_{n}^{+}=w^{+}\left(p_{n}\right)$

$\pi_{i}^{-}=w^{-}\left(p_{1}+\ldots+p_{i}\right)-w^{-}\left(p_{1}+\ldots+p_{i-1}\right) \quad$ for $1<i \leq k$

$\pi_{j}^{+}=w^{+}\left(p_{j}+\ldots+p_{n}\right)-w^{+}\left(p_{j+1}+\ldots+p_{n}\right) \quad$ for $k<j<n$

with $w^{+}$and $w^{-}$being the probability weighting function for gains and losses, respectively. Hence, the lowest negative outcome and the highest positive outcome are transformed using the respective transformation functions described in the next section. The weights for probabilities of losses (i.e., $i<k$ ) conceptually represent the marginal contribution of the respective probability to the total probability of worse outcomes and the weights for probabilities of gains (i.e., $j>k$ ) represent the marginal contribution of the respective probability to better outcomes.

For CPT, several functional forms of $v$, and $w^{+} / w^{-}$have been suggested (see Stott, 2006, for an overview). We use the classic one-parameter implementation of the value function and the weighting function suggested by Tversky and Kahneman (1992):

$$
\begin{array}{ll}
v(x)=x^{\alpha} & \text { if } x \geq 0 \\
v(x)=-\lambda(-x)^{\beta} & \text { if } x<0
\end{array}
$$


and

$$
\begin{aligned}
& W^{+}(p)=\frac{p^{\gamma}}{\left(p^{\gamma}+(1-p)^{\gamma}\right)^{1 / \gamma}} \text { if } x \geq 0 \\
& W^{-}(p)=\frac{p^{\delta}}{\left(p^{\delta}+(1-p)^{\delta}\right)^{1 / \delta}} \text { if } x<0
\end{aligned}
$$

The risk-aversion parameters $\alpha$ and $\beta$ capture the curvature of the s-shaped value function. The parameters $\gamma$ and $\delta$ capture the inverted s-shape of the weighting function, in the domains of gains and losses, respectively. The loss-aversion parameter $\lambda$ induces the increased steepness of the value function in the domain of losses. Tversky and Kahneman (1992) suggested the following parameters: $\alpha=\beta=.88, \gamma=.69, \delta=.61, \lambda=2.25$.

Let us assume that $x_{2}$ is adopted as a reference point and payoffs are perceived as differences from $x_{2}$. Consequently, $x_{2}$ has a utility of zero and $x_{1}$ has a negative (or zero) utility and the value $V_{P}$ of the prospect is given by:

$V_{P}=v\left(x_{1}-x_{2}\right) \pi_{1}^{-}=-\lambda\left(-\left(x_{1}-x_{2}\right)\right)^{\beta} w^{-}\left(p_{1}\right)$.

Choosing the cash equivalent $c$ of the prospect (equation 2) will be considered a sure loss because it will also always be smaller than $x_{2}$. According to core predictions of prospect theory, people will prefer a risky option over a sure loss with equal expected value which follows from the fact that the utility function $v$ is convex for losses. Formally, this results in the following value of the cash equivalent $V_{c}$ :

$$
V_{c}=v\left(c-x_{2}\right)=-\lambda\left(-\left(c-x_{2}\right)\right)^{\beta}
$$

And when substituting $c$ by equations 1 and 2:

$$
V_{c}=-\lambda\left(-\left(x_{1} p_{1}+x_{2}\left(1-p_{1}\right)-x_{2}\right)\right)^{\beta}=-\lambda\left(-\left(x_{1}-x_{2}\right)\right)^{\beta} p_{1}^{\beta}
$$

The difference between $V_{P}$ and $V_{c}$ is given by:

$$
V_{P}-V_{c}=-\lambda\left(-\left(x_{1}-x_{2}\right)\right)^{\beta} w^{-}\left(p_{1}\right)-\lambda\left(-\left(x_{1}-x_{2}\right)\right)^{\beta} p_{1}^{\beta},
$$

which can also be written as:

$$
\left.V-V_{c}=\left(-\lambda\left(-\left(x_{1}-x_{2}\right)\right)^{\beta}\right)\left(w^{-}\left(p_{1}\right)-p_{1}^{\beta}\right)\right)
$$

The first term of equation 11 will be negative for all $x_{2}>x_{1}$ and its magnitude increases with increasing difference between $x_{1}$ and $x_{2}$. Taking into account the values for parameters $\beta=.88$ and $\delta=.61$, mentioned above, the second term is negative for all probabilities $p_{1}>.24$; which is where the functions $w^{-}\left(p_{1}\right)$ and $p_{1}{ }^{\beta}$ intersect (Figure A1). Hence, for all $p_{1}>.24$ the value of 
the prospect is higher than its cash equivalent and (everything else being equal) the difference increases with increasing difference between $x_{2}$ and $x_{1}$.

Choices between the prospect and the cash equivalent will most likely not be deterministic. It is more likely that they follow a probabilistic function such as a logistic-choice function in which the probability for choosing one option over the other increases with its advantage in $V_{P}$ (i.e., the absolute difference between $V_{P}-V_{c}$ ).

Taking an individual differences perspective and considering only prospects with sufficiently likely lowest outcomes to prefer the prospect over the cash equivalent, the degree to which the risky prospects are preferred over the cash equivalent should increase with increasing loss aversion $\lambda$. Increasing risk aversion $\beta$ increases the magnitude of the first term, but decreases the magnitude of the second term in equation 11 , and the overall effect is therefore complex.

Figure A1: Difference in decision weights according to the second term in equation 11 as a function of probability of the lower outcome for the domain of losses.

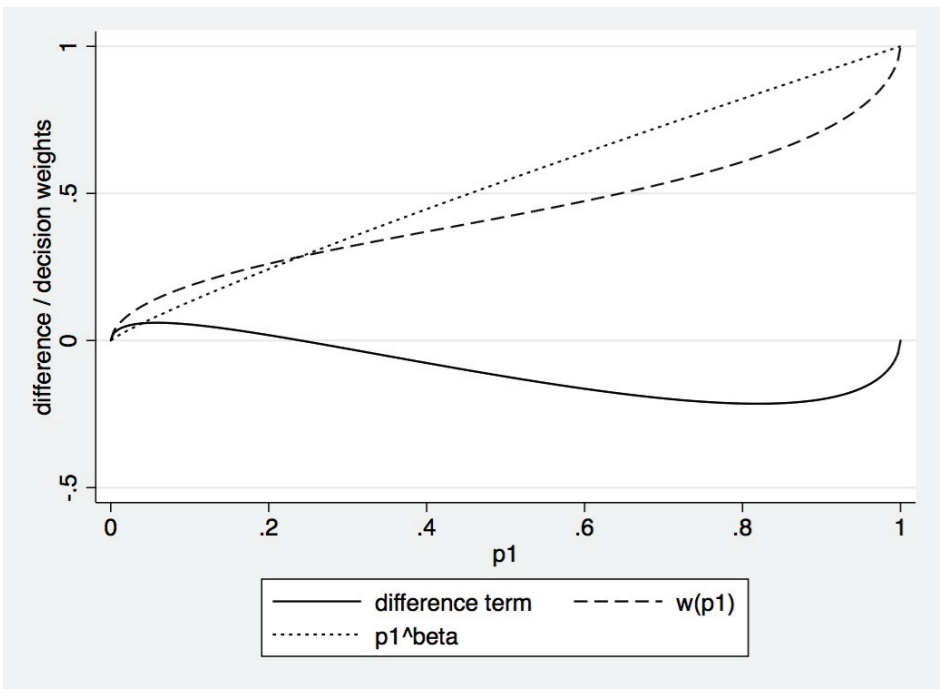

\section{Relation to Rebates}

If one accepts that rebates lead to adopting the payoff of reaching the rebate (i.e., $x_{2}=$ the maximal payoff) as reference point, then, according to CPT, rebates should induce persons to continue buying in the loyalty rebate scheme, even if an outside option has the higher expected value. This, however, should only hold when considering rebates with sufficiently large probability of failing to reach the rebate $\left(\mathrm{p}_{1}=1-\mathrm{p}_{\mathrm{R}}>.24\right)$. Hence, in our paradigm, CPT predicts entering the rebate because $1-p_{R}=.14$ and stickiness to the rebate after the critical round was omitted because $1-\mathrm{p}_{\mathrm{R}}{ }^{*}=.85$. The probability to stick to the rebate (i.e., staying in the rebate although it does not maximize expected value) should increase with increasing difference between $V_{P}$ and $V_{c}$ which is a monotonously increasing function of the difference between the high and the low overall payoff that can be reached with the rebate option. It 
should be independent of the repetitions of buying when holding the difference in payoffs constant. From an individual-difference perspective, stickiness should increase with increasing loss aversion and might be influenced in a complex way by risk aversion.

\subsection{Appendix B: Instructions}

In the first part of the experiment, you can make a buying decision in each round. There are 10 buying decisions in total. The decision is whether or not to purchase a token. You will receive information about the repeated decision in the form presented below. [Figure omitted]

Please read this information carefully now and during the experiment. In this situation, each token costs $1.10 €$ and has an exchange value of $1.30 €$; that is, at the end of the experiment, you will be credited $1.30 €$ for each token that you purchased during the experiment. In each round, you may purchase one token for the price of $1.10 €$. Alternatively, you can also decide not to purchase a token. For each round in which you decide not to buy a token, you will be credited $0.44 €$ immediately as direct payment.

At the end of the experiment, you will be granted a rebate of $49 \%$ on all purchased tokens, provided that you have purchased at least 9 tokens during the first part of the experiment. In this case, the purchase price that you spent on the tokens will be reduced by $49 \%$ to $0.56 €$.

[Figure omitted] Rounds 5 and 10 are omitted with certain probabilities. If a round is omitted, you can neither buy a token nor choose the direct payoff. Round 5 is omitted with a probability of $17 \%$ and Round 10 is omitted with a probability of $85 \%$. [Figure omitted] Dependent on whether Round 5 is omitted or not, the probability for your being able to play 9 rounds varies. Because the experiment can take different directions, depending on whether Round 5 is omitted, after Round 4 you will be asked how you will decide in Round 5 if it takes place, and how you will decide in Round 6 if Round 5 takes place. After these decisions, the computer will determine whether or not Round 5 takes place and you will make the decisions you indicated. If you decide not to buy in Round 5 and the round is played, the computer will only allow you to make this decision. If Round 5 is omitted, the computer will, for Round 6 also, only allow you to make the decision you indicated. In the following rounds, similar to Rounds 1 to 4 , you can again choose between buying the token and the direct payment.

Your payment for the first part is calculated as follows:

- If the rebate is granted:

Rounds in which tokens were bought x (Exchange value of the tokens - Price of the tokens) + Rounds in which direct payment was chosen $x$ Value of the direct payment + Price of the tokens $x$ Rounds in which tokens were bought $x$ Rebate 
- If the rebate is not granted:

Rounds in which tokens were bought $\mathrm{x}$ (Exchange value of the tokens - Price of the tokens) + Rounds in which direct payment was chosen $\mathrm{x}$ Value of the direct payment

[Instructions for measures of risk aversion and loss aversion and example calculations are omitted.]

\subsection{Appendix C: Questionnaire, Experiment 1 and 2.}

[Subjects were only allowed to proceed with the experiment once all questions were answered correctly.]

Please copy all the important parameters into the following list:

Price of tokens

Value of tokens

Minimum number of tokens bought, required to attain the rebate.

Rebate

Value of the outside option

Probability that round 5 will be omitted

$17 \%=0.17$ (please calculate in decimal fractions in this questionnaire).

Probability that round 10 will be omitted

Exercises:

1) How much do you earn in the first part of the experiment in case you buy 10 tokens?

2) How much do you earn in the first part of the experiment in case you buy 9 tokens?

3) How much do you earn in the first part of the experiment in case you buy 9 tokens and choose the outside option once?

4) How much do you earn in the first part of the experiment in case you buy 5 tokens and choose the outside option five times?

5) In the first part of the experiment, will you be able to buy 10 tokens for sure?

6) In the first part of the experiment, is it certain that you will attain the rebate if you want to? If yes, why? If no, what does getting the rebate depend on? 
7) How many decisions will you at least take in the first part of the experiment? How many at most?

8) How much will you earn in case you choose the outside option nine times?

[questions omitted that elicited the willingness to pay for not participating in the experiment that are not relevant for the current study]

9) At the beginning of the experiment, what is the probability that you will play ten rounds in the first part of the experiment?

10) At the beginning of the experiment, what is the probability that you will play nine rounds in the first part of the experiment?

11) At the beginning of the experiment, what is the probability that you will play eight rounds in the first part of the experiment?

If you find it difficult to solve exercises 12-14, consider the following tree diagram, which may help you to see what can happen in the game through omitted rounds.

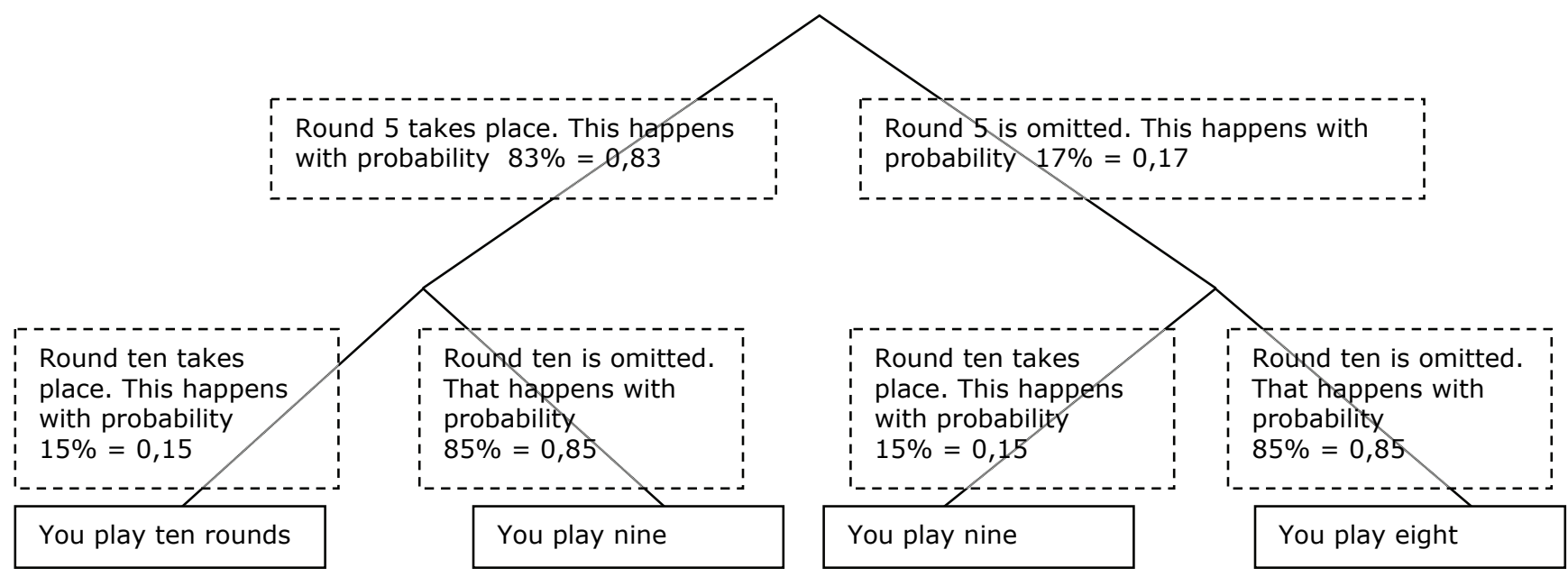

